\title{
GROUNDWATER LEVEL PREDICTION USING ARTIFICIAL NEURAL NETWORK AND M5 TREE MODELS
}

\author{
Y. Z. KAYA ${ }^{2}$, F. ÜNEŞ ${ }^{1}$, M. DEMIRCI ${ }^{1}$, \\ B. TAŞAR ${ }^{1}$, H. VARÇIN ${ }^{1}$
}

\begin{abstract}
Groundwater Level Prediction Using Artıficial Neural
Network and M5 Tree Models. Most of the fresh water resources in our world consist of underground water reserves. Estimation of fluctuations of groundwater level (GWL) is very important in the management of water resources. In this study, groundwater level (GWL) was investigated using artificial neural networks (ANN), M5tree (M5T) approaches in Reyhanlı region in Turkey. Total 196 data from 2000-2015 taken from 1 observation station belonging to Reyhanl sub-basin located in Asi basin were used in the study. Using the monthly average precipatation and temperature, the change in GWL is modeled by artificial neural networks (ANN), M5tree (M5T) approaches. The results showed that (ANN) and M5tree (M5T) models were found to be very close to each other.
\end{abstract}

Keywords: Groundwater level, Prediction, Reyhanl1, Amik plain, Artificial Neural Networks (ANN), M5tree (M5T)

\section{INTRODUCTION}

Research on groundwater is of great importance for the reason that surface water is scarce in arid and semi-arid regions. These waters, which are naturally filtered, often appear as good quality drinking and running water. Multivariate modeling is an important issue because the planning, design, and operation of water resources systems often involve meteorological and hydrological (precipitation, flow, temperature, etc.) (Pegram, 1972).

In recent years, the use of Artificial Intelligence techniques such as Genetic Programming (GP), Adaptive Neuro Fuzzy Inference System (ANFIS), Artificial Neural Networks (ANN) and M5tree (M5T) have been misinterpreted:(Unes et al (2015a, 2015b), Tasar et al (2017), Demirci et al (2017)) Coulibaly et al. (2001) applied the ANNs to model the monthly groundwater level fluctuations; Coppola et al. (2005) developed ANNs accurately estimate potentiometric surface elevations; Daliakopoulos et al. (2005), ANN Implemented for estimation of underground water level; Szidarovszky et al. (2007) presented a hybrid ANN-numerical model for groundwater problems; Coppola et al. (2007) applied a ANN model for a complex real-world underground water management problem in New Jersey; and Feng et al. (2008) applied AAN to investigate the effects of human activities on regional

\footnotetext{
${ }^{1}$ Civil Engineering Department, Iskenderun Technical University, Iskenderun, Turkey

${ }^{2}$ Civil Engineering Department, Osmaniye Korkut Ata University, Osmaniye, Turkey

E-mails: yunuszkaya@osmaniye.edu.tr, fatih.unes@,iste.edu.tr, mustafa.demirci@iste.edu.tr
} 
groundwater levels; Yang et al. (2009) applied ANN to estimate groundwater levels in China's West Jilin Province.

In this study, groundwater level measured in the previous years belonging to the Reyhanlı region was performed using Artificial Neural Networks (ANN), M5Tree (M5T) methods. Monthly total rainfall and monthly average temperature data measured at the Antakya Meteorological Station and the static underground water level monthly measurement data of the observation well No. 15768 belonging to DSI (General of State Hydraulic Works) in Reyhanlı region between 2000 and 2015 were used.

Study Area: In this study, groundwater level of Reyhanlı region on Amik plain is studied. (Figure 1.) Amik plain is the most efficient product of Turkey in productivity. It is covered with thick alluvial soil layer and is known as the most efficient rye in terms of agricultural potential. It forms the largest flat land of Hatay Province. The Amik Plain nourishes its soil primarily with Asi River, Afrin Stream and Karasu.

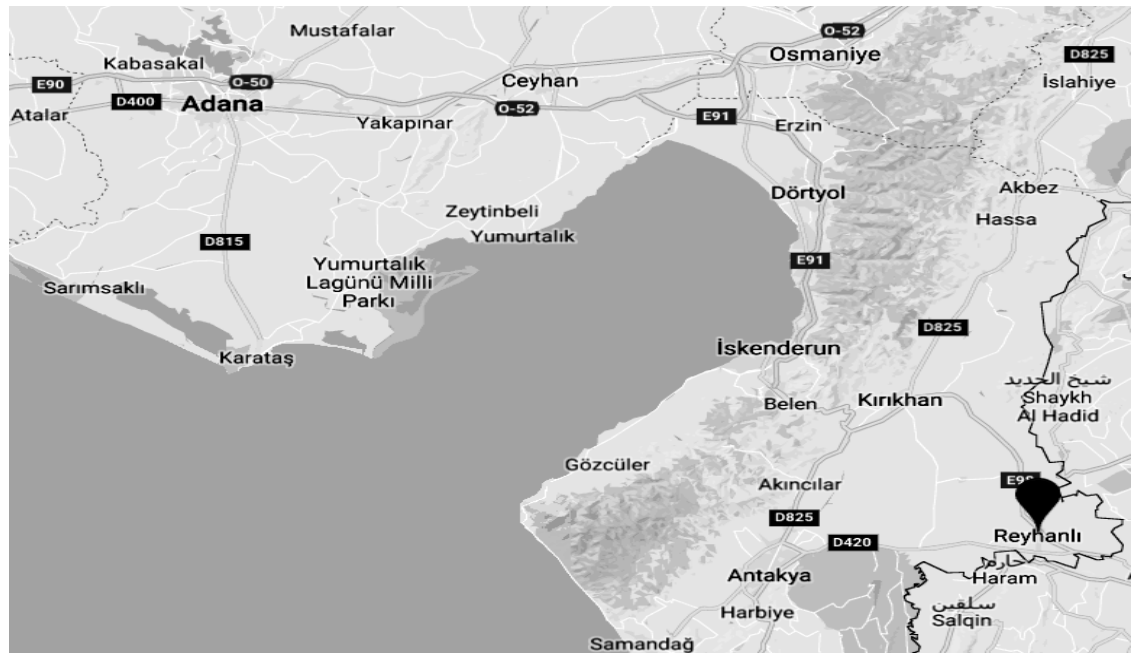

Fig. 1. Location of Reyhanlı Region (Google Maps)

\section{METHODOLOGY}

\section{Artificial Neural Networks (ANN)}

Artificial neural networks (ANN) are one of the computing techniques and systems that able to derive new information through learning from the properties of the human brain, ability to create and discover new information, developed with the aim of being able to perform without any help. Artificial neural networks; inspired by the human brain, is the result of mathematical modeling of the learning process. The most widely used method among the ANN methods is the feed- forward-backpropagation ANN approach, which operates according to the principle of back propagation of errors. An ANN model consists of input, hidden and output layers with their nodes. ANN Structure used in this study is given in Figure 2. 


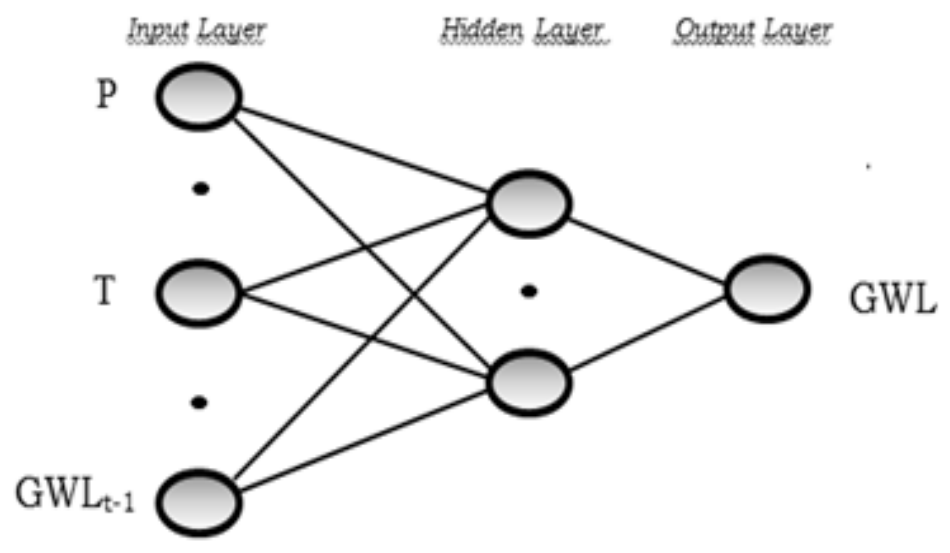

Fig. 2. ANN Structure Used in this study

\section{M5 Tree (M5T)}

M5 approach was introduced by Quinlan (1992). M5 is a system that creates tree-based and segmented linear models. This model involve classification which generate decision trees. Model tree production takes place in these stages: The first stage involves using a partitioning criterion to form a decision tree. The partitioning criterion for the M5 tree approach algorithm is based on the assumption that the standard deviation of the values of a node accessing class is a measure of the error in that node and then constructing a test for each attribute when computing the expected decrease in this error. The formula of standard deviation reduction $(\Delta)$ given below:

$$
\Delta=s d(T)-\sum \frac{\left|T_{i}\right|}{|T|} s d(T i)
$$

where $s d$ is symbolize of the standard deviation, $\mathrm{T}$ is a set of instances that gets at the node, $\mathrm{Ti}$ is the subset of instances that have the its outcome of the potential set (Wang, and Witten,1997). After all possible tests have been obtained, M5 selects the test which maximizes this expected "error reduction". Readers who want to learn more about the M5 model tree, can examine Quinlan (1992).

\section{RESULTS}

In this study, the monthly groundwater level data measured in Reyhanl, DSI (General of State Hydraulic Works) data and the monthly total rainfall and monthly average temperature data measured at the Antakya Meteorological Station were used to determine groundwater level. Models were carried out using 192 data of monthly ground water level, monthly total precipitation and monthly average temperature values measured for 16 years between 2000 and 2015 . 


\section{ANN model results}

ANN model was employed for groundwater level prediction. The distribution and scatter graphs are shown in Figure 3 and Figure 4.

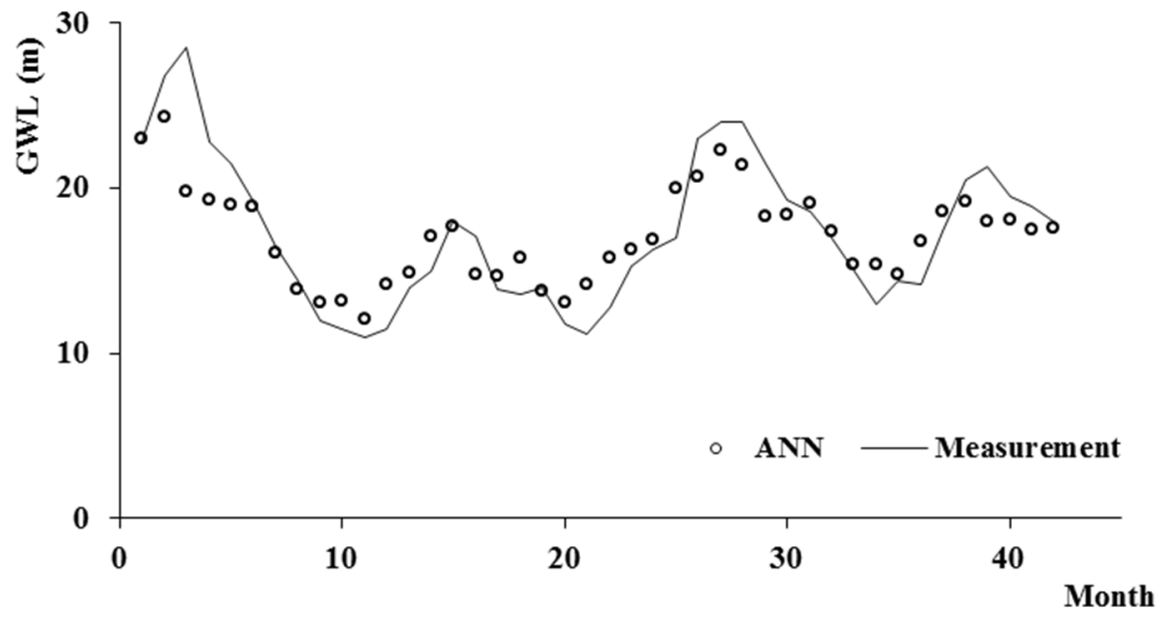

Fig. 3. Measurement and ANN distribution chart for groundwater level for test data.

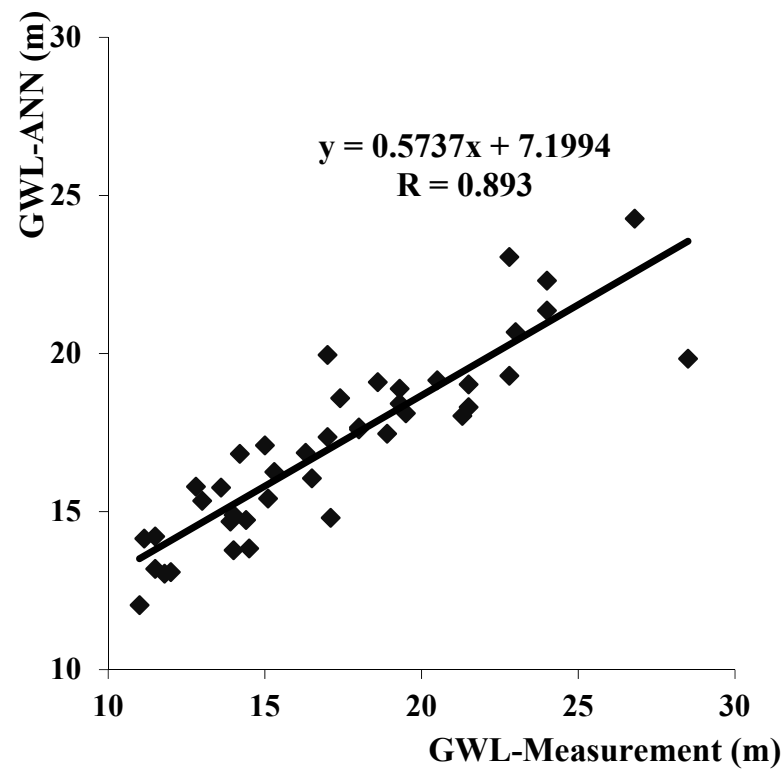

Fig. 4. Measurement and ANN model scatter graph for groundwater level for test data.

Results of ANN model show that the correlation coefficient is high and the groundwater level estimate is closer to the actual values shown in figure 3 . The correlation coefficient $\mathrm{R}=0.893$ was obtained as seen the figure 4 . 


\section{M5 Tree (M5T) Model Results}

In the M5 Tree (M5T) Model, 144 data of 192 were used for training and 48 data were analyzed for the test. Monthly Mean Precipitation (MP), Monthly Average Temperature (MT), Monthly Ground Water Level $(\mathrm{GWL}+1)$ were used for the Ground Water Level estimations. Estimated testing results are shown in Figs. 5 and 6 as, respectively, the distribution and scatter plots.

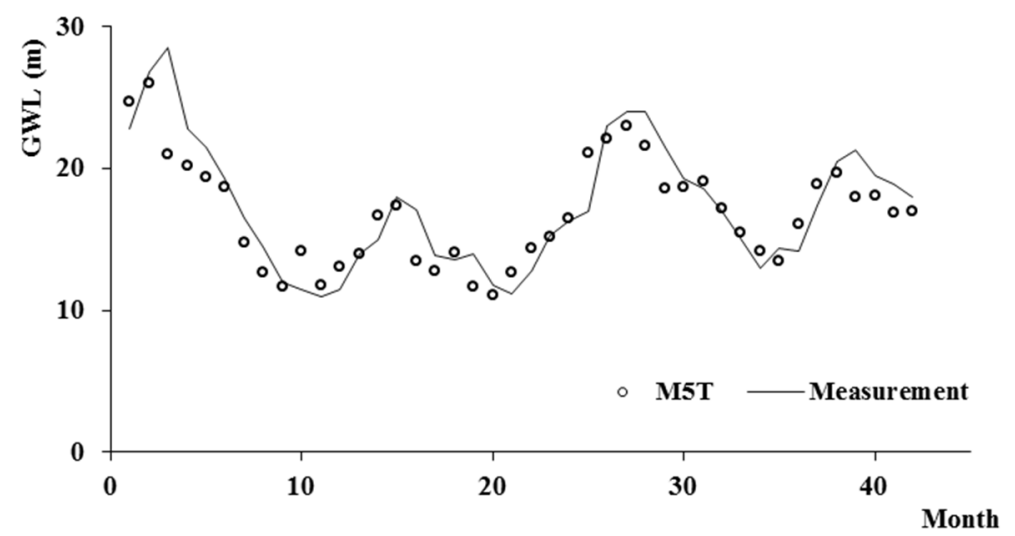

Fig. 5. Distribution graph of monthly M5T results

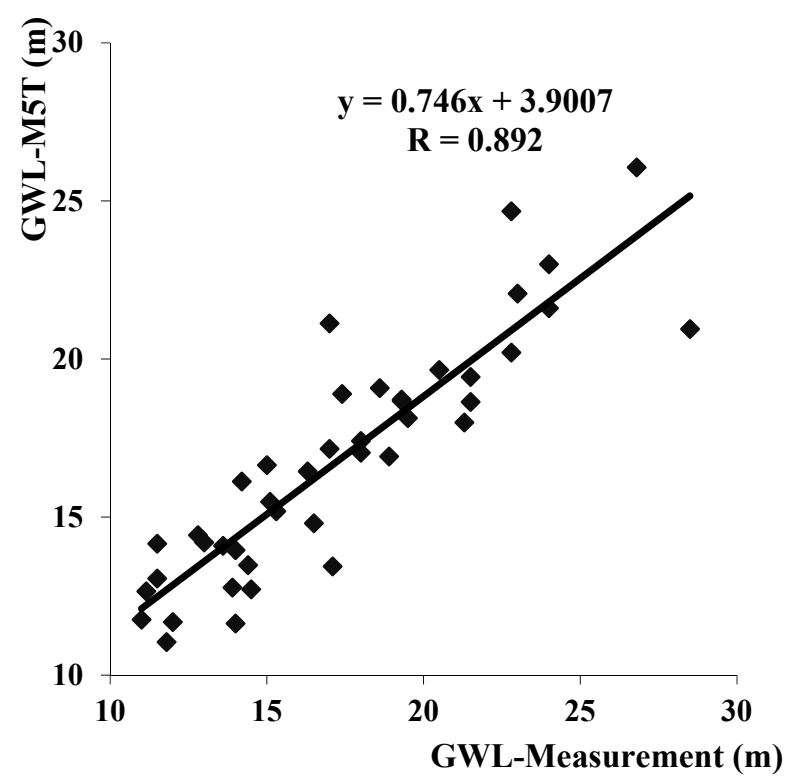

Fig. 6. Scatter graph of M5T and observed values 
The M5T estimated values were observed in the test phase and gave closer results according to the ANN values. The correlation coefficient $\mathrm{R}=0.892$ was obtained as seen the figure 5. M5T model results data are close to the actual values shown in figure 4.

\section{General Evaluation}

The correlation coefficient (R), mean square error (MSE) and absolute mean error (MAE) for the performance evaluation of the ANN and M5T models are calculated. For each model, mean square error (MSE) and mean absolute error (MAE) are computed Results are used to compare the performance of model prediction and the observation data. Comparing parameters of MSE, MAE and R obtained from testing data are shown in Table 1.

Table 1. MSE: Mean square error, MAE: Mean absolute error, $R$ : Correlation coefficient

\begin{tabular}{cccc}
\hline Model & MSE & MAE & $\mathrm{R}$ \\
\hline ANN & 2,26 & 1,71 & 0,893 \\
M5T & 2,05 & 1,55 & 0,892 \\
\hline
\end{tabular}

\section{CONCLUSION}

In this study, monthly total rainfall, monthly mean temperature and monthly groundwater level data of Reyhanlı region were used for the groundwater level prediction. Artificial Neural Networks (ANN) and M5tree (M5T) models were investigated in order to improve the methods to estimate the groundwater level. The accuracy of the ANN and M5T models in groundwater level estimation were also investigated, and the results were compared with each other. Comparisons revealed that the ANN and M5T model had the closer accuracy in the groundwater level and both method can be used to predict groundwater level.

\section{REFERENCES}

1. Quinlan, JR. (1992), Learning with continuous classes. Proceedings of Australian Joint Conference on Artificial Intelligence. World Scientific Press: Singapore; 343-348.

2. Wang, Y., Witten, IH. (1997), Induction of model trees for predicting continuous lasses. In: Proceedings of the Poster Papers of the European Conference on Machine Learning. University of Economics, Faculty of Informatics and Statistics, Prague.

3. Coulibaly, P., F. Anctil, and B. Bobfe, (2001), Multivariate reservoir inflow forecasting using temporal neural networks, J. Hydrol. Eng., in press, 2001. 
4. Coppola, E., C. McLane, M. Poulton, F. Szidarovszky, and R. Magelky. (2005a), Predicting conductance due to upconing using neural networks. Ground Water 43, no. 6: 827-836.

5. Daliakopoulos, I., P. Coulibaly, and I. Tsanis. (2005), Ground water level forecasting using artificial neural networks. Journal of Hydrology 309, no. 1-4: 229-240.

6. Coppola, E., F. Szidarovszky, and D. Davis. (2007), Multiobjective analysis of a public wellfield using artificial neural networks. Ground Water 45, no. 1: 53-61.

7. Szidarovszky F, Coppola E, Long JJ, Hall AD, Poulton MM. (2007), A hybrid artificial neural network-numerical model for ground water problems. Ground Water 45: 590-600.

8. Feng SY, Kang SZ, Huo ZL, Chen SJ, Mao XM. (2008), Neural Network to simulate regional ground water levels affected by human activities. Ground Water 46(1): 80-90.

9. Google Maps. (2017, November 10). Retrieved from https://www.google.com.tr/maps/place/Reyhan

10. Pegram, G. G. S., James, W. (1972), Multilag Multivariate, Autoregressive Model for the Generation of Operational Hydrology. Water Resources Research, 8, 10741076.

11. Yang CT, Reza M, Aalami MT (2009), Evaluation of total load sediment transport using AAN. International Journal of Sediment Research 24(3):274-286.

12. Demirci, M., Üneş, F., Kaya, Y. Z., Mamak, M., Tasar, B., Ispir, E. (2017), Estimation of groundwater level using artificial neural networks: a case study of Hatay-Turkey. Environmental Engineering 10th International Conference, Vilnius Gediminas Technical University-Lithuania. DOI: https://doi.org/10.3846/enviro.2017.092

13. Üneş, F. and Demirci, M. and Kişi, Ö., (2015a), Prediction of millers ferry dam reservoir level in usa using artificial neural network, Periodica Polytechnica Civil Engineering, 59, 309-318.

14. Üneş, F. and Demirci, M. (2015b), Generalized Regression Neural Networks for Reservoir Level Modeling. International Journal of Advanced Computational Engineering and Networking, 3, 81-84.

15. Tasar, B, Kaya, Y. Z., Varcin, H., Üneş, F., Demirci, M. (2017), Forecasting of Suspended Sediment in Rivers Using Artificial Neural Networks Approach, International Journal of Advanced Engineering Research and Science (IJAERS), 4(12), pp. 79-84. 